\title{
The Web of Risk Factors for Excessive Gestational Weight Gain in Low Income Women
}

\author{
Keriann H. Paul ${ }^{1}$, Meredith L. Graham ${ }^{1}$, and Christine M. Olson ${ }^{1,2}$ \\ ${ }^{1}$ Division of Nutritional Sciences, Cornell University, Ithaca, NY
}

\begin{abstract}
Objectives-To gain an in-depth understanding of issues related to gestational weight gain (GWG) including general health, diet, and physical activity among high- and low-income women and to elucidate socio-ecological and psychosocial risk factors that increase risk for excessive gestational weight gain.

Methods-We conducted 9 focus groups with high ( $\mathrm{n}=4$ groups) and low ( $\mathrm{n}=5$ groups) income pregnant women aged 18-35 years to discuss health, GWG, diet and physical activity following a discussion guide. The constant comparative method was used to code focus group notes and to identify emergent themes. Themes were categorized within the integrative model of behavioral prediction.
\end{abstract}

Results-Low income women, in contrast to high income women, had higher BMIs, had more children, and were African American. Diet and physical activity behaviors reported by low income women were more likely to promote positive energy balance than were those of high income women. The underlying behavioral, efficacy, and normative beliefs described by both groups of women explained most of these behaviors. Experiencing multiple risk factors may lead to 1) engaging in several behavior changes during pregnancy unrelated to weight and 2) holding more weight gain-promoting beliefs than weight maintaining beliefs. These factors could inhibit diet and physical activity behaviors and/or behavior changes that promote energy balance and in combination, result in excessive GWG.

Conclusions-Low income women experience multiple risk factors for excessive GWG and successful interventions to prevent excessive GWG and pregnancy related weight gain will need to recognize the complex web of influences.

\section{Keywords}

excessive gestational weight gain; low income; beliefs; diet; physical activity

\section{Introduction}

Pregnancy related weight gain contributes to obesity in women over their lifespan (1). Additionally, gaining too much in pregnancy increases the risk of infant macrosomia and child overweight (2). The most important predictor of postpartum weight retention is

\footnotetext{
${ }^{2}$ Corresponding Author: 352 Martha Van Rensselaer, Ithaca, NY 14853; cmo3@ cornell.edu; phone 607-255-2634; fax 607-255-0178.
} 
gestational weight gain (GWG), and the prevalence of excessive GWG, defined as gaining above the Institute of Medicine's (IOM) recommended weight gain range, is high $(2,3)$. Thus, avoiding excessive gestational weight gain could be an effective approach to preventing postpartum weight retention and obesity in women and their children.

Low income women have been found to be at higher risk for both inadequate and excessive GWG (4-7). Attempts to identify additional risk factors for inappropriate GWG have not been successful in observational epidemiological studies. Olson et al developed a biopsychosocial model to predict excessive gestational weight gain, but found that no psychosocial variables remained significant in a model that included household income and diet and physical activity behaviors (7). Recently, a review of potential socio-ecological and psychosocial risk factors in the 2009 IOM report, "Weight Gain During Pregnancy:

Reexamining the Guidelines," found that few of these risk factors could conclusively be deemed determinants of GWG (2). The authors of the IOM report call for studies to be conducted to understand the "social, cultural, and environmental contexts of gestational weight gain." Larger quantitative studies may be limited in this pursuit due to the interactions between underlying risk factors and household income. Qualitative studies may be useful for describing the relationships among such complex phenomena (8).

The qualitative studies conducted in pregnant women about gestational weight gain have typically focused on one particular population group such as African Americans (9), Hispanics (10), whites (11), overweight/obese women $(12,13)$, and low or high income women $(11,14)$. Additionally, the studies often cover only one aspect such as weight gain $(12,15)$, physical activity $(13,16)$, or diet $(11,14)$. Lastly, older qualitative studies in low income women only cover issues related to inadequate weight gain with little or no discussion of excessive gestational weight gain $(9,14)$. The objectives of this study were to gain an in-depth understanding of issues related to gestational weight gain including general health, diet, and physical activity among high- and low-income women and to elucidate socio-ecological and psychosocial risk factors that increase risk for excessive gestational weight gain. This study was conducted as part of the formative research for the development of a large, community-based intervention for prevention of excessive gestational weight gain and postpartum weight retention.

\section{Methods}

We conducted nine focus groups with high ( $\mathrm{n}=4$ groups) and low ( $\mathrm{n}=5$ groups) income pregnant women aged 18-35 years in Rochester, Monroe County, NY. The income cutoff was whether or not women were eligible for WIC and/or Prenatal Care Assistance Program (PCAP), about $185 \%$ of the US Federal Poverty Line. Focus groups were advertised through flyers at obstetrics practices, Child Care Council, Inc. of Rochester, and a local health and parenting program for low income women. When women called to volunteer for the study, the recruiter scheduled them for either the high income focus groups or low income focus groups based on whether or not women responded that they received WIC or PCAP. No other criteria were used to divide women into groups, although we added one extra low income focus group to attempt getting more white low income participants. Focus group topics included women's beliefs and behaviors around health, weight gain, diet, and physical 
activity during pregnancy (Table 1). The focus group discussion guide was designed following the methods of Krueger (17). Women received $\$ 40$ cash as a gift for participating.

One researcher (M. Graham) moderated the discussions while another researcher (K. Paul) observed and recorded detailed notes on the women's responses, interactions, and physical appearances. The detailed notes captured as many of the verbatim responses as possible. The researchers debriefed immediately after each focus group to discuss prominent themes according to the methods of Krueger $(17,18)$. The observer listened to the recordings after each focus group to fill in the rest of the verbatim responses following Krueger's note-based analysis method. The constant comparative method was used to code focus group notes and to identify additional emergent themes (19). Both researchers discussed and agreed on the final themes. Themes on the women's beliefs and behaviors were categorized within the integrative model of behavioral prediction by Fishbein and Yzer (20) which is the guiding theory for the intervention being developed. The model states that behaviors are directly predicted by a strong intention to perform the behavior in addition to an individual's skill level and amount of environmental constraints. Intentions are in turn influenced by the set of behavioral beliefs (what outcome will occur if I do this behavior), normative beliefs (what do other people tell me is the right behavior), and efficacy beliefs (what do I believe I am capable of doing) that a person holds and values related to that behavior. Participants provided written informed consent. All study procedures were approved by the Institutional Review Boards of Cornell University, Unity Health System, and the Child Care Council, Inc. of Rochester.

\section{Results}

A total of 15 low income women and 11 high income women, who were currently pregnant, participated in the focus groups (Table 2). Recruitment was lower for the high income pregnant women, but theoretical saturation was reached with the sample size. Low income pregnant women were mostly African American. There were about as many overweight/ obese women as normal weight women among low income women. High income women, in contrast, were more often white and normal weight. Low income women in the sample reflected the demographic composition of the city of Rochester while higher income women reflected the composition of Monroe County. Thirteen percent of individuals live below the poverty level in Monroe County, which is similar to the US overall, but that figure is more than doubled inside the city of Rochester at $29.1 \%$. The racial and ethnic population distribution in Monroe County is 78.9\% white, 14.3\% African American, and 5.9\% Hispanic compared to Rochester which is $49.3 \%$ white, $39.8 \%$ African American, and 13.5\% Hispanic (21). Parity was higher among low income women.

While discussing topics related to health, weight gain, diet, and physical activity, women in both high and low income groups described many of their diet and physical activity behaviors. Diet and physical activity behaviors reported by low income women were more likely to promote positive energy balance than were those of high income women. For instance, low income women described eating energy dense foods (fast foods, fried foods, soda, high fat toppings on vegetables, etc.), overeating (binge eating and eating large portions), eating few fruits and vegetables (only eating fruits and just eating one or two 
types of vegetables), and walking only in association with daily living. High income women mentioned soothing cravings and nausea with healthy foods, choosing less energy dense foods to satisfy increased appetites, eating small, frequent meals to prevent hunger, bringing lunch from home to avoid overeating at work, and maintaining exercise frequency.

Both groups of women were also engaged in behavior change during their pregnancy, but the focal behaviors were very different. High income women discussed their trying to increase certain nutrients in their diet such as protein and fiber, modifying their exercise routine to be lower impact, switching to all organic foods, taking more time to relax and destress, and avoiding harmful foods in pregnancy such as lunch meat, soft cheese, and caffeine. Low income women, however, were quitting or reducing smoking, quitting drug use, abstaining from drinking, and beginning to eat fruits and vegetables.

The underlying behavioral, efficacy, and normative beliefs described by both groups of women explained most of these behaviors and behavior changes (Table 3). Both groups of women believed that eating healthy foods like fruits and vegetables was good for their baby's health, and most believed that diet was a major contributor to GWG. At the same time, low income women held many other beliefs that led to less healthy diet and physical activity behaviors. One major behavioral belief was that women sometimes ate when they felt stressed, depressed, or overwhelmed in order to feel better (i.e. emotional eating). One woman said she wanted to be by herself to be less stressed and noted that her boyfriend said she is always, "sitting in my room with mini-cheesecakes and brownie bites." Another behavioral belief was that any walking was considered sufficient physical activity. An 8months pregnant woman explained, "My bedroom is upstairs, and the bathroom is downstairs. I go about 10-15 times a day. That's enough exercise."

Behavioral beliefs of high income women supported their maintenance of healthy behaviors. Women strongly believed that eating too much food leads to excessive GWG, and to a lesser extent, that physical activity helped slow the rate of weight gain. This belief came more from information seeking than any type of social norm as one woman describes, "I think some people use it as an excuse. 'I can eat whatever I want' or 'I'm eating for two.' But I read in one of the books, you're really only eating for 1.1." Also, women believed that eating healthfully and being active during pregnancy made one feel better in general, "It's the whole mental aspect of it. When you're exercising, those endorphins are sending all the good things to your brain and you feel GREAT!"

The normative beliefs that the low income women mentioned also explained their behaviors. Eating for two and indulging in cravings was felt to be the status quo during pregnancy. Partners and families members actively supported the "eat for two" notion asking women, "What are you craving tonight?" Women enjoyed telling stories of just how badly they craved certain foods and what lengths they took to get what they wanted. After saying she was trying to eat less during pregnancy, a woman confessed, "I would pay for the ride to McDonalds, even if it took \$10.” Women's consumption of energy dense foods was also associated with normative food preferences where women talked about local preferences for soul food, barbecue and meat in general. Similarly, several comments about food prepared or purchased by extended family members indicated that some women regularly relied on 
parents and grandparents to provide food, whether healthy or unhealthy instead of always getting food for themselves. Describing the types of vegetables recommended to her by her doctor, a young woman retorted, “They said you can eat cabbage. I don't eat cabbage, but I eat collard greens. So I told my grandma to make me some collard greens, but who's going to make collard greens every other day? Not my grandma." This woman went on to complain that if she gained too much weight it would be her family's fault. Related to the behavioral belief that any walking is sufficient is the normative belief that activity associated with daily living is the major source of physical activity. Three women did mention going to the gym for exercise but it was only in reference to exercise before or after pregnancy. Lastly, despite recognition that eating a lot of food caused weight gain, two normative beliefs about health demonstrate why that knowledge is not particularly salient. One is that lower weight does not mean better health, “just because you're skinny doesn't mean you're healthy," and two, quitting smoking and other substance abuse is the greatest health priority in pregnancy.

There were fewer prominent normative beliefs described by high income women that explained their behaviors. Physical activity as structured/recreational exercise and as activity associated with daily living was encouraged, but structured/recreational exercise was encouraged more. Women did report that the idea of eating for two was prominent among other women such as female relatives and work peers. Only one woman indicated that she was somewhat swayed by this belief, "I think any woman sees it as an excuse to eat more food. You gotta give (make) a good little pad there." However, most women ignored this belief as mentioned previously.

Efficacy beliefs among low-income women reflected low self-efficacy. For instance, women mentioned being unable to exercise because they were tired, busy with kids, or physically uncomfortable. In general, women believed you could not control weight gain during pregnancy for reasons like not being able to resist cravings. When the moderator would prompt, "Can you think of some ways a woman can control the amount of weight she gains," in one focus group the women laughed and all said, "No." Another woman mentioned, "go to sleep." Women also explained why they could not do more physical activity because they "get tired and have no help at home" or "get fat and can't move."

High income women's efficacy beliefs were mostly positive, and but some were negative. Women believed they could soothe cravings and avoid eating unhealthfully, "Now that I'm pregnant, my body needs other things. I've had to kind of follow those cravings, but I try to do it in a healthful way." Similarly, women talked about being able to control food consumption and therefore weight gain during certain periods of pregnancy which balanced out periods with less control, "I remember I had the urge to eat. At one point I was almost in tears. I just wanted this to go away. I tried to eat gum. Eventually it went away. There were a couple of days when you don't even want food so it balances out." Women were also confident they could maintain physical activity despite pregnancy discomfort by modifying their routine, "I've had a lot of joint problems so walking is more painful now. So I'm starting a water arthritis class to try to get things going. My hips have been a wreck so anything I used to do like treadmill at the gym isn't really that great. I've had to change my activity." One woman was concerned about controlling her weight gain due to her past 
struggles with weight, but she also mentioned feeling motivated to eat healthy because she had a purpose for this weight gain, the health of her baby, "I'm a little bit obsessive about it right now just because I've always been heavier, so I'm even more conscious of that now knowing that my weight and how I haven't taken care of myself is now affecting somebody else. However, high income women were less confident in their ability to lose weight quickly in the postpartum period and maintain physical activity in bad weather.

Low income women brought up several issues that related to the socio-ecological and psychosocial factors predicted to affect GWG. These issues can be linked to their existing beliefs and behaviors. Stress and depression were often mentioned as initiators to emotional eating, and experiencing multiple hardships can increase stress and depressive symptoms. Women talked about dealing with custody issues, child care, negative partner relationships, lack of social support, seeking therapy for depression, and unintended pregnancies. Poor food environments were brought up in terms of a lack of places to purchase healthy foods and a surplus of fast food restaurants from which to eat and satisfy cravings. Cultural norms led to some of the negative beliefs and non-diet related behavior changes. Women lived in extended families as most were unmarried and young. Therefore they were not responsible for shopping or cooking. Teenage pregnancy was considered the norm in this population which explains why parity was so high in this age group; many of our participants had had their first child before the age of 18. Cultural food preferences (both African American and Hispanic) included many high- fat and fried foods that were mentioned as pregnancy cravings and excluded a variety of fruits and vegetables that were recommended by health care providers. Women talked about a high prevalence of substance abuse in the community and being users since they were teenagers. Media was mentioned several times with regard to disturbing anti-smoking public service announcements which helped motivate women to quit smoking.

\section{Discussion}

Diet and physical activity behaviors reported by low income women were more likely to promote positive energy balance than were those of high income women. The data from high income women serve as a comparison to highlight the distinct differences in behaviors and underlying beliefs that put low income women at high risk for excessive gestational weight gain. These results also provide some initial evidence for a potential framework that connects many of the predicted psychosocial and socio-ecological risk factors to diet and physical activity behaviors in low income women. We developed a conceptual framework as a "working hypothesis" ((22) pg. 225) for energy balancing behaviors and behavior changes in low income women based on underlying factors related to these weight gain-promoting beliefs (Figure 1) . Low income women appear to experience multiple risky socio-ecological and psychosocial factors during pregnancy. In the top path, experiencing these risk factors leads directly to weight-promoting behavioral, normative, and efficacy beliefs. Holding these weight-promoting beliefs would obviously inhibit women from performing energy balancing behavior as expected based on the Integrative Model of Behavioral Prediction. Along the bottom path, a new insight is that experiencing these risk factors leads women to engage in several, often simultaneous behavior changes, such as smoking cessation and alcohol cessation that could limit them from initiating other positive changes related to 
energy-balancing behaviors. Most of these behavior changes were not motivated by any long-term goals, as indicated by many women reporting repeated behavior of resuming smoking after each pregnancy, or enacted using any type of theory-based behavior change program, such as a structured smoking cessation program, and therefore can even contribute to more unhealthy diet behaviors.

The socio-ecological and psychosocial characteristics for this population and the risks associated with them are well known, and the interconnections among them are daunting. Not only were our low income participants more often minorities, they were also more often overweight or obese. Psychosocial factors like stress and depression are common among low income (23), minority $(24,25)$, and obese $(26,27)$ women. Enduring multiple hardships, as discussed in this study, that might potentially lead to stress and depression are highly prevalent in low income women during pregnancy with $14 \%$ of low income women experiencing 4 or more hardships (28). Poor food environments are associated with low income, urban, minority populations (29). Low income populations have higher rates of smoking, and the most common cluster of behavioral health risks are smoking, poor diet, and low physical activity $(30,31)$. Minorities have further challenges such that abstinence rates after smoking cessation attempts are lower than for white smokers (30).

Low income women possessed several beliefs related to poor diet and physical inactivity in general, which is consistent with the literature: fruits and vegetables taste bad $(32,33)$; eating makes you feel better $(34,35)$; energy dense foods are preferable $(32,33)$; partners and friends support poor diets (33); weight is not equal to health $(33,36,37)$; physical activity is activity associated with daily living, not exercise (38); and extended family are responsible for cooking (33). From this study, it is evident that the state of pregnancy seems to exacerbate these behaviors due to additional weight gain promoting beliefs: ok to indulge in cravings and eat for two; fruits and vegetables cause heartburn; any activity is sufficient; substance cessation is the most important health priority; women can't be active because they are tired and physically uncomfortable. Additionally, pregnancy can exacerbate these beliefs by contributing added sources of stress and depression. Beliefs about health in general de-emphasized weight in this low income population. Low income women had smoking and substance cessation as their highest priority. The disconnect between weight and health may come partially from the well-known different perceptions of body image among African American women and partially from the association of thinner body types to long-term drug use (36). The obese African American women considered themselves healthier than their thin, drug addicted peers. Substance-abuse disorders have been found to lower the risk of obesity in African Americans (24). Consequently, these pregnant women seemed more proactive towards health behavior changes around smoking and substance abuse and more reactive towards behavior changes around weight (i.e. I'll do whatever my body tells me to do).

Income-related factors were rarely linked to weight-promoting beliefs by the low income women. Food insecurity, participation in food assistance programs, and cost of food are often associated with poor diets and obesity $(32,39,40)$. In our study, food insecurity was not mentioned, and participation in food assistance programs (only WIC) was mentioned twice. We found this striking considering those topics were mentioned several times in our 
follow-up study among postpartum mothers (manuscript in preparation). Cost of healthy food was only mentioned by high income women. This finding highlights the potential to make incorrect assumptions about why low income women are at risk of excessive GWG and how to address this risk through interventions.

Multiple health risks (MHR) such as smoking, alcohol abuse, substance abuse, poor diet, and inactivity are common in low income populations which was evident in this study. Coordinated thinking and research about addressing MHR through multiple health behavior changes (MHBC) is relatively recent (41). Multiple health behavior changes are advocated in pregnancy (smoking/alcohol/drug cessation and higher consumption of nutrient dense foods). However, these multiple behavior changes, especially in low income women, have not been viewed in this MHBC context and should be, given the severity of the many discrete, negative health outcomes related to these MHR that manifest over this short period of time. Women often attempt these MHBC without any theory-based behavior change program (42). The data presented here highlight the potential consequences. None of our participants mentioned using any structured resource for smoking, alcohol, or drug cessation. Only women diagnosed with gestational diabetes $(n=2)$ or at risk of low infant weight gain $(n=2)$ were given special nutrition counseling to make dietary changes. Considering weight gain is associated with smoking cessation as well as cessation of other drugs, ignoring smoking cessation might lead to diminished intervention effects. Polley et al hypothesized that attention to such substance abuse issues by their low income subjects may have contributed to their diet and physical activity intervention's having a negative effect on rates of excessive GWG among overweight, low income women (43).

A major research question for MHBC is how effective simultaneous behavior change is compared to sequential behavior change. The hypothesis for simultaneous behavior change is that mediators required for one behavior change are similar enough to those for other behavior changes so individuals should be able to leverage the behavior change process to change multiple behaviors at once (44). The alternative hypothesis is that individuals may become overwhelmed trying to change multiple behaviors at once and there would be intervention interference necessitating a sequential approach (41). Neither simultaneous nor sequential order had an effect on a physical activity and dietary fat intervention (44). Studies looking at smoking cessation and prevention of weight gain though have found that a sequential behavior change intervention (smoking then diet/physical activity) was most effective for preventing smoking relapse and slowing rate of weight gain (45). Future research is needed to determine the optimal overlap of MHBC interventions for smoking, diet, and physical activity in pregnancy to achieve prompt cessation of smoking and other substances as well as appropriate rates of weight gain.

The limitations of this study are those associated with qualitative research. Sample sizes are small, and participants are recruited purposively rather than randomly. In addition, small sample sizes prevent statistical hypothesis testing being done in qualitative data. Results cannot be generalized to a larger population, and are meant to provide an understanding of depth and context related to the focal issue of excessive GWG. The differences between income groups could represent the racial and ethnic composition of the two groups.

Recruitment of low income white women and conversely, high income minority women, 
was difficult considering the demographic make-up of the population. Focus group responses from two low income white participants did not deviate much from the responses of other low income women. More low income women were observed to have higher BMIs than the high income women, which might also explain some of the group differences. Again this reflects US demographics where by obesity prevalence in women increases as income decreases, and thus true income differences would be difficult to disentangle from BMI differences in the US (46).

In conclusion, low income pregnant women in this urban setting exhibited far more weightpromoting behaviors and related underlying behavioral, normative, and efficacy beliefs than high income pregnant women. These beliefs may likely contribute to the increased risk of excessive gestational weight gain. Being low income encompasses a complex web of risk factors. Interventions can target these beliefs and underlying risk factors to promote behavior changes that will lead to appropriate weight gains in pregnancy.

\section{Acknowledgements}

We would like to acknowledge the Child Care Council, Inc. of Rochester, the Healthy Start Center, Unity Health System, and the Perinatal Network of Monroe County for their help in recruiting and providing space to conduct the focus groups. The study was supported by NIH Grant No. U01HL096760 with funding from the National Heart, Lung and Blood Institute (NHLBI) and the Eunice Kennedy Shriver National Institute of Child Health \& Human Development (NICHD). The content is solely the responsibility of the authors and does not necessarily represent the official views of the National Heart, Lung and Blood Institute or the National Institutes of Health.

\section{References}

1. Phelan S. Pregnancy: a "teachable" moment" for weight control and obesity prevention. Am J Obstet Gynecol. 2010; 202:e1-8.

2. IOM (Institute of Medicine), Council) NNR. Weight Gain During Pregnancy: Reexamining the Guidelines. The National Academies Press; Washington, D.C.: 2009.

3. Gore SA, et al. The role of postpartum weight retention in obesity among women: A review of the evidence. Ann Behav Med. Oct.2003 26:149-59. [PubMed: 14534032]

4. Wells CS, et al. Factors Influencing Inadequate and Excessive Weight Gain in Pregnancy: Colorado, 2000-2002. Matern Child Health J. 2006; 10:55-62. [PubMed: 16496222]

5. Hickey CA. Sociocultural and behavioral influences on weight gain during pregnancy. Am J Clin Nutr. May.2000 71:1364S-70S. [PubMed: 10799414]

6. Lederman SA, et al. Pregnancy-associated obesity in black women in New York City. Matern Child Health J. Mar.2002 6:37-42. [PubMed: 11926252]

7. Olson CM, Strawderman MS. Modifiable behavioral factors in a biopsychosocial model predict inadequate and excessive gestational weight gain. J Am Diet Assoc. 2003; 103:48-54. [PubMed: 12525793]

8. Krathwohl, D. Methods of Educational and Social Science Research: An Integrated Approach. 2nd. Waveland Press, Inc.; Long Grove, IL: 2004.

9. Everette M. Gestational Weight and Dietary Intake During Pregnancy: Perspectives of African American Women. Matern Child Health J. 2007; 12:718-24. [PubMed: 17987371]

10. Tovar A, et al. Knowledge, Attitudes, and Beliefs Regarding Weight Gain During Pregnancy Among Hispanic Women. Matern Child Health J. 2009

11. Copelton DA. "You are What You Eat": Nutritional Norms, Maternal Deviance, and Neutralization of Women's Prenatal Diets. Deviant Behav. 2007; 28:467-94.

12. Wiles $\mathrm{R}$. The views of women of above average weight about appropriate weight gain in pregnancy. Midwifery. 1998; 14:254-60. [PubMed: 10076321] 
13. Weir Z, et al. Physical activity in pregnancy: a qualitative study of the beliefs of overweight and obese pregnant women. BMC Pregnancy Childbirth. 2010; 10:18. [PubMed: 20426815]

14. Fowles ER, et al. Identifying healthy eating strategies in low-income pregnant women: applying a positive deviance model. Health Care Women Int. Oct.2005 26:807-20. [PubMed: 16214795]

15. Groth SW, Kearney MH. Diverse Women's Beliefs About Weight Gain in Pregnancy. J Midwifery Womens Health. 2009; 54:452-7. [PubMed: 19879517]

16. Cioffi J, et al. Physical Activity in Pregnancy: Women's Perceptions, Practices, and Influencing Factors. J Midwifery Womens Health. 2010; 55:455-61. [PubMed: 20732667]

17. Krueger, R. Moderating Focus Groups. Sage Publications; Thousand Oaks, CA: 1997.

18. Krueger, R. Focus Groups: A Practical Guide for Applied Research. Sage Publications; Thousand Oaks, CA: 1994.

19. Strauss, AL.; Corbin, JM. Basics of qualitative research : techniques and procedures for developing grounded theory. 2nd. Sage Publications; Thousand Oaks: 1998.

20. Fishbein M, Yzer MC. Using theory to design effective health behavior interventions. Commun Theory. May.2003 13:164-83.

21. US Census Bureau. 2005-2009 American Community Survey. 2009. [cited 2011 12/13/2011]; Available from: http://factfinder.census.gov/servlet/DatasetMainPageServlet? _program=ACS\&_submenuId=\&_lang=en\&_ds_name=ACS_2009_5YR_G00_\&ts=

22. Merriam, SB. Qualitative research : a guide to design and implementation. 2nd. Jossey-Bass; San Francisco: 2009.

23. Koleva H, et al. Risk factors for depressive symptoms during pregnancy. Arch Womens Ment Health. 2010; 14:99-105. [PubMed: 20872153]

24. Rosen-Reynoso M, et al. The relationship between obesity and psychiatric disorders across ethnic and racial minority groups in the United States. Eat Behav. 2011; 12:1-8. [PubMed: 21184966]

25. Joseph JG, et al. Reducing Psychosocial and Behavioral Pregnancy Risk Factors: Results of a Randomized Clinical Trial Among High-Risk Pregnant African American Women. Am J Public Health. 2009; 99:1053-61. [PubMed: 19372532]

26. Laraia BA, et al. Pregravid Weight Is Associated With Prior Dietary Restraint and Psychosocial Factors During Pregnancy. Obesity. 2009; 17:550-8. [PubMed: 19131943]

27. Scott KA, et al. Obesity and mental disorders in the adult general population. J Psychosomat Res. Jan.2008 64:97-105.

28. Braveman P, et al. Poverty, Near-Poverty, and Hardship Around the Time of Pregnancy. Matern Child Health J. 2008; 14:20-35. [PubMed: 19037715]

29. Fleischhacker SE, et al. A systematic review of fast food access studies. Obes Rev. 2011; 12:e460e71. [PubMed: 20149118]

30. Matthews AK, et al. Development of a Culturally Targeted Smoking Cessation Intervention for African American Smokers. J Community Health. 2009; 34:480-92. [PubMed: 19728056]

31. Fine LJ, et al. Prevalence of multiple chronic disease risk factors. Am J Prev Med. 2004; 27:18-24. [PubMed: 15275670]

32. Lucan SC, et al. Promoters and barriers to fruit, vegetable, and fast-food consumption among urban, low-income African Americans--A qualitative approach. Am J Public Health. 2010; 100:631-5. [PubMed: 20167885]

33. James D. Factors influencing food choices, dietary intake, and nutrition-related attitudes among African Americans: Application of a culturally sensitive model. Ethn Health. 2004; 9:349-67. [PubMed: 15570680]

34. Bove CF, Olson CM. Obesity in low-income rural women: Qualitative insights about physical activity and eating patterns. Women Health. 2006; 44:57-78. [PubMed: 17182527]

35. Hargreaves MK, et al. Contextual factors influencing the eating behaviors of African American women: A focus group investigation. Ethn Health. 2002; 7:133-47. [PubMed: 12523941]

36. Lovejoy M. Disturbances in the social body: Differences in body image and eating problems among African American and White women. Gend Soc. 2001; 15:239-61. 
37. Ristovski-Slijepcevic S, et al. Being 'thick' indicates you are eating, you are healthy, and you have an attractive body shape: Perspectives on fatness and food choice amongst Black and White men and women in Canada. Health Sociol Rev. 2010; 19:317-29.

38. Dietz W. Focus group data pertinent to the prevention of obesity in African Americans. Am J Med Sci. Nov.2001 322:275-8. [PubMed: 11721801]

39. Leung CW, Villamor E. Is participation in food and income assistance programmes associated with obesity in California adults? Results from a state-wide survey. Public Health Nutrition. 2010; 14:645-52. [PubMed: 20701819]

40. Olson CM. Nutrition and health outcomes associated with food insecurity and hunger. J Nutr. Feb. 1999 129:521S-4S. [PubMed: 10064322]

41. Prochaska JJ, et al. Multiple health behavior change research: An introduction and overview. Prev Med. 2008; 46:181-8. [PubMed: 18319098]

42. Crozier SR, et al. Do women change their health behaviours in pregnancy? Findings from the Southampton Women's Survey. Paediatr Perinat Epidemiol. Sep.2009 23:446-53. [PubMed: 19689495]

43. Polley BA, et al. Randomized controlled trial to prevent excessive weight gain in pregnant women. Int J Obes Relat Metab Disord. Nov.2002 26:1494-502. [PubMed: 12439652]

44. Vandelanotte $\mathrm{C}$, et al. A randomized trial of sequential and simultaneous multiple behavior change interventions for physical activity and fat intake. Prev Med. 2008; 46:232-7. [PubMed: 17707079]

45. Spring B, et al. Randomized Controlled Trial for Behavioral Smoking and Weight Control Treatment: Effect of Concurrent Versus Sequential Intervention. J Consult Clin Psychol. 2004; 72:785-96. [PubMed: 15482037]

46. Ogden, CM., et al. NCHS Data Brief. National Center for Health Statistics; Hyattsville, MD: 2010. Obesity and socioeconomic status in adults: United States 1988-1994 and 2005-2008. 


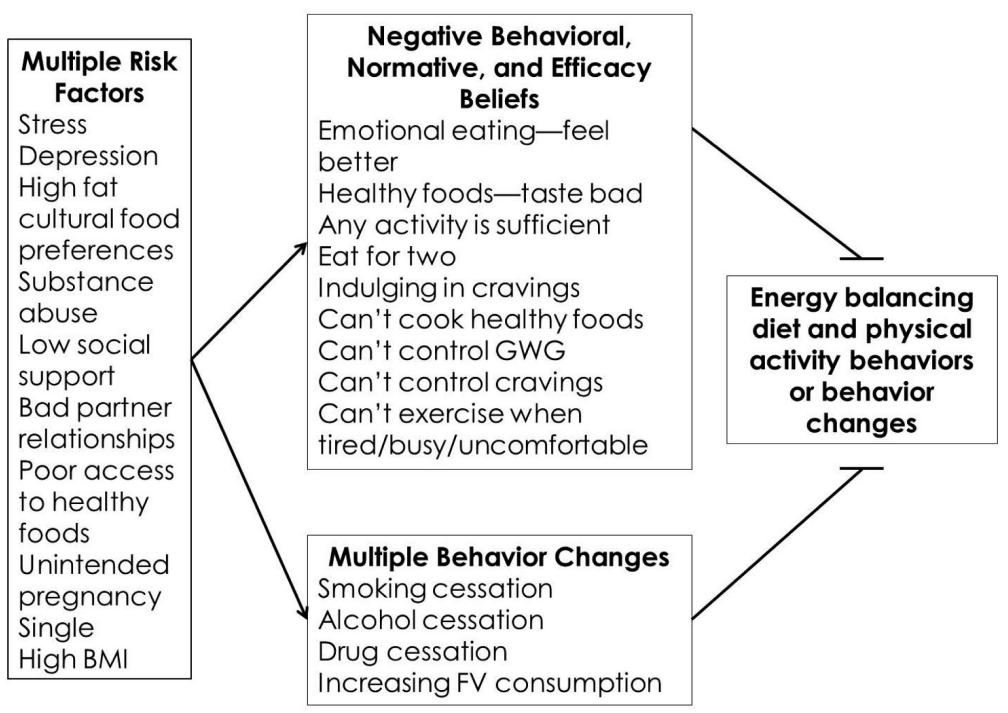

Figure 1.

Conceptual framework for the inhibition of energy balancing behaviors and behavior changes among low income women during pregnancy. 


\section{Table 1}

Focus group discussion questions

\begin{tabular}{lcll}
\hline Section & Question & \\
\hline General health & $\mathbf{1}$ & What are some of the things you are thinking about more now that you are pregnant? \\
& $\mathbf{2}$ & Considering all of these priorities, how would you rank your health among all of these thing \\
& $\mathbf{3}$ & What does it mean to you to be healthy during pregnancy? \\
Weight gain & $\mathbf{1}$ & Where does the weight you are gaining fit in with being healthy during pregnancy? \\
& $\mathbf{2}$ & What have you heard about how much to weight to gain during pregnancy? \\
& $\mathbf{3}$ & What do you think influences or determines how much a woman gains during pregnancy? \\
Diet & $\mathbf{1}$ & How does what a woman eat fit in with gaining weight? \\
& $\mathbf{2}$ & What are ways a woman can control the amount she eats? \\
& $\mathbf{3}$ & How has your diet changed since you've been pregnant? \\
Physical & $\mathbf{1}$ & How does a woman's physical activity fit in with gaining weight? \\
activity & & How has your physical activity changed since you've been pregnant? \\
\hline
\end{tabular}

Matern Child Health J. Author manuscript; available in PMC 2015 August 13. 


\section{Table 2}

Participant characteristics

\begin{tabular}{lcc}
\hline & Low income & High income \\
\hline Focus groups, $\mathrm{n}$ & 5 & 4 \\
No. of women, $\mathrm{n}$ & 15 & 11 \\
Race/Ethnicity ${ }^{1}$, n (\%) & & \\
• African American & $11(73)$ & 0 \\
• Asian & 0 & $1(9)$ \\
• Hispanic & $3(20)$ & 0 \\
• White & $4(27)$ & $10(91)$ \\
BMI ${ }^{1}$, n(\%) & & \\
• Normal weight & $7(47)$ & $8(73)$ \\
• Overweight/obese & $8(53)$ & $3(27)$ \\
Parity, n(\%) & & \\
• Nulliparous & $7(47)$ & $9(82)$ \\
• Primiparous & $1(6)$ & $1(9)$ \\
• Multiparous & $7(47)$ & $1(9)$ \\
\hline
\end{tabular}

${ }^{1}$ Observed, not self-reported 
Table 3

Determinants of behaviors in low and high income women

\begin{tabular}{|c|c|}
\hline Low income & High income \\
\hline \multicolumn{2}{|c|}{ Behavior beliefs } \\
\hline $\begin{array}{l}\text { Eating fruits and vegetables is good for the } \\
\text { baby }\end{array}$ & $\begin{array}{l}\text { Eating fruits and vegetables is good for the } \\
\text { baby }\end{array}$ \\
\hline Eating makes you feel better when stressed & Eating too much causes excessive GWG \\
\hline Certain fruits and vegetables cause heartburn & Eating healthy makes you feel better \\
\hline \multirow[t]{2}{*}{ Any amount of walking is exercise } & $\begin{array}{l}\text { Exercise will make you feel better during } \\
\text { pregnancy }\end{array}$ \\
\hline & Exercise will slow rate of weight gain \\
\hline \multicolumn{2}{|c|}{ Normative beliefs } \\
\hline Indulge in cravings & Weight to be lost postpartum \\
\hline Eat for two & Physical activity is structured and recreational \\
\hline $\begin{array}{l}\text { Quitting smoking, drinking, and drug use most } \\
\text { important thing in pregnancy }\end{array}$ & $\begin{array}{l}\text { Activity associated with daily living is physical } \\
\text { activity }\end{array}$ \\
\hline \multicolumn{2}{|l|}{ Weight not equal to health } \\
\hline \multicolumn{2}{|l|}{ Preferred foods are high fat, fast food } \\
\hline \multicolumn{2}{|l|}{$\begin{array}{l}\text { Activity associated with daily living is physical } \\
\text { activity }\end{array}$} \\
\hline \multicolumn{2}{|c|}{ Efficacy beliefs } \\
\hline Can't cook healthy foods & Can soothe cravings in a healthy way \\
\hline Can't control cravings, binges & Can control weight gain somewhat \\
\hline Can't control weight gain & Postpartum weight loss is hard \\
\hline Can't exercise when tired & Can control food intake at certain periods \\
\hline Can't exercise when feel uncomfortable & Can't exercise when weather is bad \\
\hline Can't exercise when busy & $\begin{array}{l}\text { Can modify activities to maintain physical } \\
\text { activity }\end{array}$ \\
\hline
\end{tabular}

